\title{
O humor na estratégia de persuasão durante as campanhas eleitorais
}

\author{
Humor in political marketing strategy during election \\ campaigns
}

O humor é um fenômeno universal (Weinberger 1991), característico do comportamento humano ${ }^{1}$, e tem sido concebido de diferentes maneiras. Por exemplo, para Roperto (2010), o humor é uma arte que surge como parte das sociedades democráticas como uma ferramenta para a crítica dos poderes estabelecidos (ver Roperto, s/d). Humor ou humorismo (do latim: humor, oris-) ${ }^{2}$ foi definido, também, como a forma de apresentar, processar ou comentar a realidade, destacando o lado cômico, alegre ou ridículo das coisas. ${ }^{3}$

Para Sigmund Freud, "o humor é a mais alta manifestação de mecanismos de enfrentamento do indivíduo" (1928, p. 2), enquanto, para Paul Reboux, o humor "é simplesmente tratar as coisas sérias com leveza, e com seriedade as coisas leves" (1950, p. 56). Humor é também uma arma de sobrevivência, um método para o conforto humano. Nesse sentido, Nietzsche afirmou que "o homem sofre tão profundamente que ele teve que inventar o riso"

É professor do Centro Universitario de Ciencias Económico Administrativas da Universidade de Guadalajara (Guadalaraja, México). E-mail: azepeda@cucea.udg.mx.

** É professora do Centro Universitario de Ciencias Económico Administrativas da Universidade de Guadalajara (Guadalaraja, México).

*** É professora do Centro Universitario de Ciencias Económico Administrativas da Universidade de Guadalajara (Guadalaraja, México).

O humor está sempre presente no homem, manifestando-se como bom, ruim ou indiferente.

A origem da palavra humor vem da teoria dos quatro humores corporais da medicina grega, que regulam o estado de ânimo: a bile, o catarro, o sangue, a bile negra ou outra bile. O caráter humorístico corresponde ao humor sanguíneo.

Este artigo, incluindo as citações, foi traduzido ao português por Miguel Flores Zepeda. 
(1994, p. 3-4). Nesse sentido, é um meio para tornar mais agradável, e gratificante, a existência humana.

O humor sempre acompanhou a política. Desde os tempos antigos, o humor foi usado como parte das estratégias satíricas e irônicas do povo para criticar os maus governos. Assim, por um longo tempo, os comediantes foram perseguidos pelo poder político estabelecido. Depois, o humor foi usado como parte das estratégias das elites dominantes para entreter e agradar as pessoas ou dissuadi-las de criticar o poder estabelecido.

Figuram, por exemplo, na história da Grécia, Esopo e Aristófanes. O primeiro viveu no século VI a.C. e era famoso por suas fábulas e o sarcasmo contra as elites religiosas. ${ }^{4} \mathrm{O}$ segundo viveu durante o século IV a.C. e também foi reconhecido por suas comédias em que se valia de uma linguagem incisiva e sarcástica a favor do Partido Aristocrata em Atenas e contra os democratas. ${ }^{5}$ Enquanto isso, na Roma antiga, surge Fredo, como fabulista lúdico e moralizador, bem como Marciais e Luciano, que foram célebres comediantes, apoiando-se na poesia, epigramas e sátiras. ${ }^{6}$

Hoje em dia, o humor é usado como uma estratégia política para construir a liderança e conseguir persuadir, informar e entreter as massas. Na verdade, uma das marcas da verdadeira liderança é o uso apropriado do humor, uma vez que um indivíduo triste, sombrio, amargo, irritado e, acima de tudo, frugal e chato, dificilmente será seguido pelas pessoas. ${ }^{7}$

O humor tem sido usado como um meio de fazer os outros rirem, entreter e melhorar as relações interpessoais, mas também, para fins políticos, se usa o humor como sarcasmo, ironia ou para caricaturar e difamar adversários. Em campanhas eleitorais, o humor é usado por partidos e candidatos como um meio para gerenciar o afeto dos eleitores, persuadir, gerar atenção e empatia, para que o candidato seja compreendido e lembrado e até mesmo para provocar mudanças nas atitudes e comportamento dos eleitores.

Douglas (1975) acredita que os líderes em sistemas ditatoriais tendem a limitar e censurar o humor na mídia

Quintiliano foi um dos primeiros a sugerir em seu livro De institutione oratória, o uso do humor como parte das estratégias de persuasão no discurso público.

6 Cícero afirmou que um orador precisafazer as pessoas rirem para convence-las, e que através do uso de piadas e risadas, ele pode desarmar acusações contra ele e que não são facilmentere futáveis pelas evidencias.

É importante notar que há variações culturais de humor, que podem fazer com que o que é divertido em um lugar seja desprovido de graça em outro. Isso se deve porque o contexto influencia o humor. 
Por que usar o humor como estratégia de persuasão em campanhas eleitorais? Qual é o efeito gerado pelo uso do humor na conduta e comportamento dos eleitores? Quais as vantagens competitivas geradas pelo uso do humor no processo eleitoral, como parte da estratégia de marketing político? Essas são algumas das perguntas que tentaremos responder neste artigo.

\section{Estado da arte}

O humor como ferramenta de marketing tem sido estudado desde os anos 1980, principalmente nos Estados Unidos e na Europa, onde se tenta entender, por exemplo, o efeito do humor em aspectos como persuasão, capacidade de chamar a atenção, atitudes em relação à marca, minorias e compreensão, entre outros (Cifuentes, 2005). A maioria desses trabalhos se concentrou no estudo do negócio e da empresa. No entanto, pouco tem sido estudado como uma ferramenta ou meio para gerenciar o afeto dos eleitores, persuadir, mobilizar e conseguir influenciar a orientação de voto dos cidadãos (a favor ou contra) quanto a determinado partido, candidato ou plataforma eleitoral (Bippus, 2007). Como se disse, os estudos existentes foram realizados principalmente nos EUA e na Europa. No caso da América Latina, os estudos sobre essa área de especialização são quase inexistentes.

No âmbito empresarial, os estudos feitos sobre o humor como um meio de propaganda concluem que é uma ferramenta que afeta a intenção de compra (Smith, 1993) e facilita o processo de persuasão dos consumidores, ajudando também na construção ou reforço de marca (Lyttle, 2001; Madden e Weinberger, 1982; Zhang, 1996; Chatttopadhyay e Basu, 1989; Scott, Klein e Bryant, 1990). Outros estudos sugerem que o humor é muito eficaz, também, como forma de captar a atenção do consumidor, tendo um efeito positivo sobre a atenção para a publicidade comercial (Stewart e Furse, 1982; Weinberger e Campbell, 1991; Madden e Weinberger, 1982) e sobre a atenção dos alunos no campo educacional (Powell e Andersen, 1985; Bryant e Zillmann, 1979).

Por outro lado, alguns estudos concluem que o humor, usado como estratégia de publicidade, também ajuda a melhor compreensão por parte dos consumidores da mensagem transmitida, o que é de grande interesse durante as campanhas promocionais (Weinberger e Gulas, 1992; Cantor e Vênus, 1980; Dunkan, Nelson e Frontczak, 1983; Zhang e Zinkhan, 1991). 
Da mesma forma, outros estudos sugerem que o humor também ajuda a fazer com que as marcas sejam lembradas e mais bem reconhecidas pelos consumidores, atuando como um reforço positivo (Weinberger e Campbell, 1991; Chung e Zhao, 2003; Furnham, 1998). Sobre o efeito de propagandas bem-humoradas, alguns estudos concluíram que geram atitudes positivas em relação às marcas anunciadas, encontrando-se uma relação positiva entre humor e atitude para com o anúncio (Mitchell e Olson, 1981; Zhang, 1996; Belch e Belch, 1984; Gelb e Pikett, 1983; Ray e Batra, 1983; Lyttle, 2001). Sylvester (2000) observa que o humor na publicidade também é altamente eficaz porque age como um diferencial entre produtos similares. Finalmente, outros estudos concluíram que o sucesso da publicidade de humor depende do meio que a transmite (Weinberger et al., 1995; Madden e Weinberger, 1984; Weinberger e Campbell, 1991), das diferenças culturais entre os consumidores (Alden, Mukherjee e Hoyer, 2000), e até mesmo do sexo (Gallivan, 1992, 1976; Cantor, Terry e Ertel, 1974).

Dentro da arena política, não é necessário dizer que há poucos estudos sobre o uso do humor como estratégia de persuasão em campanhas eleitorais ou como recurso para alcançar o poder. Sobressai o trabalho de Lopez (2008), que encontrou no humor um recurso simbólico de poder, que faz parte do capital cultural e gera um empoderamento da pessoa que o utiliza corretamente. Enquanto isso, Tsakona (2009) estudou o uso do humor no discurso parlamentar, analisando o caso da Grécia, lembrando que ele tem sido utilizado como parte das estratégias para atacar o inimigo, para garantir informalidade aos processos parlamentares ou para criar uma identidade única para os seus promotores. Finalmente, há as obras de Vasil Evich (2005) sobre humor político e a análise da sua utilização ao longo da história como parte do processo político e a de Bippus (2007) sobre a eficácia do uso do humor como parte do debate político e sobre o uso de humor nas campanhas eleitorais e seus efeitos sobre o público.

\section{Humor e liderança}

Em sistemas políticos democráticos, a administração adequada do humor torna-se uma ferramenta estratégica para construir e manter o consenso social necessário na construção de liderança, de acesso, ou de conservação do poder. Na verdade, ao enumerar as qualidades distintivas de um bom líder, quase nunca se negligencia (ou se deixa de considerar) seu bom senso 
de humor. Ou seja, o senso de humor é essencial para afetar as relações interpessoais necessárias à liderança.

Em tais sistemas, apoiados em consensos sociais e por maiorias eleitorais estáveis, o humor se torna uma ferramenta indispensável para a gestão do afeto dos cidadãos e para conseguir sua aprovação e aquiescência. Por outro lado, sob regimes autoritários ou totalitários, baseados em imposição, coerção e violência, o humor não é muito útil ${ }^{8}$, já que esses sistemas não são suportados por um consenso social e pelo voto livre e esclarecido dos cidadãos. ${ }^{9}$

O uso do humor como estratégia de persuasão e de construção de imagem (marca) só é possível em sistemas políticos democráticos, sustentados pela concorrência, pluralidade e liberdade de escolha. Na verdade, o uso inteligente do humor nesses sistemas torna-se uma vantagem competitiva na luta para manter ou alcançar posições de poder político. A capacidade de fortalecimento que fornece o riso baseia-se na obtenção de um consenso. Quando o público concorda com a associação ou declaração feita pelo "comediante", que pode ser um político, o público se manifesta de acordo com a sua decisão por meio do riso (Lopez, 2008). Esse consenso, mesmo temporário, pode afetar o comportamento político das pessoas em um contexto eleitoral, da mesma forma que, por exemplo, uma pessoa mal-humorada é classificada como triste, amarga ou ruim (Sanchez Alvarez, 2007).

Nesse contexto, o humor é um elemento que faz parte do capital cultural, de propriedade da pessoa que o exerce (Lopez, 2008). O bom desempenho desse humor pode capacitar os indivíduos, facilitando as relações interpessoais e a comunicação, tão necessárias para a liderança.

Daniel Goleman (2001) aponta que o bom humor é característica de bons líderes e o mau humor, de líderes ruins, e que o humor é contagiante. Um líder pessimista e mal-humorado espalha raiva, desconfiança e maus desempenhos, enquanto um líder otimista e de bom humor motiva os colaboradores. A esse respeito, John Maxwell (2009) argumenta que um líder com senso de humor consegue melhorar o ambiente de trabalho em até $67 \%$ mais do que um líder que não tem essa qualidade.

8 Às vezes, em sistemas totalitários e autoritários, os governantes são apoiados pelo humor negro. De acordo com o Dicionário da Real Academia Espanhola, humor negro é um "humor exercido sobre as coisas que aumentam, visto de outra perspectiva, piedade, terror, ou emoções similares." Em tais sistemas, o humor negro é usado, em qualquer caso, como um instrumento de coerção.

A este respeito Vasil' Evich (2005) observa que Ivan, o Terrível, o czar russo, usou o humor em forma de ironia. 
Uma pesquisa em particular centrou-se na frequência com que um grupo de executivos provocou o riso do entrevistador e, em seguida, realizou um acompanhamento longitudinal desses indivíduos ao longo de um período de dois anos para observar quais deles acabavam por tornarem-se executivos "estrela". Essa investigação revelou que os líderes de mais destaque eram aqueles que conseguiram despertar o riso do entrevistador com uma frequência duas vezes maior que a média dos executivos (Madrigal, 2010).

De acordo com o Madrigal (2010), independentemente do estresse da situação, os líderes mais eficazes recorrem ao humor mais frequentemente e ao mesmo tempo transmitem mensagens positivas que modulam o clima emocional subjacente. Em outras palavras, o humor funciona como um dispositivo para ajudar a criar um clima melhor entre os indivíduos, o que contribui para a construção da liderança. ${ }^{10}$

Como observado por Castellvi (2010), o "senso de humor e a criação de um clima ou ambiente agradável deve ser uma das habilidades de um bom líder. A capacidade de rir demonstra um alto grau de conhecimento, inteligência e autocontrole e é a melhor maneira de atrair outras pessoas" (Castellvi, 2010, p. 2-4).

\section{As funções políticas do humor}

O humor tem diferentes funções em sociedades com sistemas políticos democráticos. ${ }^{11}$ Essas características explicam por que o humor é frequentemente usado como estratégia de propaganda na política, a fim de alcançar os objetivos organizacionais pretendidos.

Em primeiro lugar, o humor proporciona uma maior visibilidade social dos políticos, contribuindo para melhor captar a atenção dos cidadãos e dos próprios meios de comunicação.

\footnotetext{
${ }^{10}$ Rod A. Martin (2007) observa que o humor nem sempre indica as competências sociais e pessoais, já que às vezes pode revelar problemas de personalidade. Ou seja, é uma faca de dois gumes, pois tanto pode facilitar as relações pessoais como pode ser um fator erosivo dessas relações. Por exemplo, tanto o humor depreciativo como o autodepreciativo são comportamentos que afetam as relações pessoais ou a sua autoestima. O primeiro é usado para criticar e manipular os outros por meio do sarcasmo provocante, ou do ridículo, enquanto o segundo é usado para denegrir-se a si mesmo, o que pode mascarar episódios de ansiedade e autodesprezo. Nesse sentido, Morreal (2010) observa que aquele que usa o humor como estratégia de comunicação não é honesto com as pessoas; além disso, o humor reflete certo vazio, engano, hedonismo, hostilidade e irresponsabilidade.

11 Para o neurologista Lee Berk, o riso diminui o cortisol, um hormônio que causa estresse no organismo, e que também potencializa maior atividade entre as células linfócitas, que são responsáveis por buscar uma boa resposta imunológica.
} 
Segundo, facilita o processo de persuasão, funcionando como um estímulo comunicacional para influenciar crenças, atitudes e comportamentos dos cidadãos.

Em terceiro lugar, ele serve como um meio para insultar e ridicularizar os adversários. Na verdade, essa é uma prática muito comum na política, na qual se busca ridicularizar e denegrir a concorrência. Nesse caso, o humor é geralmente invocado para mostrar a incoerência e o absurdo das ações ou posições políticas propostas pelos adversários (Tsakona, 2009).

Em quarto lugar, o humor gera uma atitude positiva e boa vontade entre os ouvintes, uma vez que um dos objetivos do humor é fazer as pessoas rirem, é agradar e seduzir o público. ${ }^{12}$ No entanto, para alcançar essas metas é importante saber o esquema referencial (experimental) do público e do contexto (situação) que está sendo vivenciado.

Em quinto lugar, o humor ajuda a gerar um maior nível de memorização, e ajuda aos eleitores a melhor lembrar aquelas frases, discursos e eventos políticos em que o humor estava presente.

Em sexto lugar, melhora a compreensão da mensagem transmitida, ajudando a melhorar a comunicação política. Usar metáforas como forma humorada permite transmitir mensagens e uma melhor comunicação.

Em sétimo lugar, o humor ajuda a alcançar uma verdadeira diferenciação e identidade. Os cidadãos tendem a identificar melhor os políticos com bom senso de humor e aqueles cujo principal dom é saber como fazê-los sorrir. Na verdade, um dito popular diz: "Uma vez que você fez as pessoas rirem, não importa o que você diz, já os tem na bolsa".

Em oitavo lugar, o político bem-humorado ajuda a elevar o humor do público e a superar os momentos difíceis, cheios de tensão, porque o riso é uma das experiências mais prazerosas da vida. Nesse sentido, os psicólogos descobriram que um bom senso de humor é uma das ferramentas mais poderosas para enfrentar e superar os fracassos, caos e desastres que podem ocorrer, por exemplo, durante as campanhas eleitorais. ${ }^{13}$

Em nono lugar, o humor tem um grande poder de unir as pessoas e proporcionar a coesão de um grupo, ${ }^{14}$ ajudando a formar, por exemplo,

\footnotetext{
12 De acordo com Jorge Madrigal Fritsch (2010) reúne o riso, entre outros, o papel de mobilizar os centros emocionais dos membros da equipe a uma atitude positiva. Em outras palavras, o riso não é apenas uma expressão gestual de felicidade, é também um mecanismo rápido para o alívio emocional.

13 Ver Sandra E. Ritz (2004).

14 Ver Gary A. Fine (1983).
} 
equipes de campanha altamente competitivas. ${ }^{15}$ Ou seja, o humor tem um grande poder de coesão e, portanto, é um remédio ideal para remover barreiras e superar diferenças e tensões que possam surgir dentro das equipes de campanha.

Finalmente, o humor afeta a orientação do voto dos cidadãos. Ou seja, gera um efeito sobre as decisões de voto e de motivação política do eleitor.

Para cumprir seu objetivo comunicacional, o humor precisa ser usado com moderação (sem abuso) e de acordo com o perfil experiencial e cultural do público que procura influenciar, porque o humor não é o cômico, mas sim a capacidade de percebê-lo.

\section{O humor nas campanhas eleitorais}

O humor é usado em campanhas eleitorais porque produz resultados, influenciando o ânimo dos eleitores e afetando seu comportamento. De acordo com Freud (1928), o humor cria um efeito benéfico nos seres humanos, pois oferece relaxamento e melhora as relações interpessoais.

Durante as campanhas eleitorais, os candidatos costumam usar o humor como uma estratégia de comunicação apelando para as anedotas, piadas, frases famosas, provérbios e, acima de tudo, por meio do uso de ironia e sarcasmo. ${ }^{16}$ Com essa ferramenta de diversão, o candidato se comunica e melhor expressa a sua mensagem. Obtém também maior ligação emocional com os seus eleitores, podendo tocar áreas sensíveis e mobilizar emoções primárias do indivíduo.

Para milhões de pessoas, a vida se apresenta como uma representação trágica da sua existência: como eles vivem, muitas vezes na miséria, cheios de problemas e frustrações, vivendo em cidades desumanas e neuróticas, onde coabitam a violência, a tragédia e a infelicidade, eles estão ansiosos por representações cômicas que gerem momentos de alegria e felicidade, mesmo que sejam fugazes ou curtos. Ou seja, o eleitor é um público ávido pelo humor. Assim, o candidato encontra um terreno fértil para persuadir o público a partir de uma estratégia de comunicação apoiada no humor. ${ }^{17}$

\footnotetext{
${ }^{15}$ A unidade é definida quando o código é gerado entre os membros da equipe

${ }^{16}$ Dominar a arte de entreter e fazer as pessoas rirem é um processo de treinamento e aprendizagem em médio e longo prazo, que muitas vezes se baseia na tentativa e erro

17 É bem conhecido que o humor desempenha uma função catártica semelhante a das lágrimas. Neste sentido, o riso produz benefícios, o nível de endorfinas e relaxamento das audiências. Da mesma forma, é sabido que a mente humana precisa de refresco, relaxar, ter alguns momentos de alegria,
} 
Fazer rir é uma arte, que pode ser dominada com a persistência, prática e criatividade. Para ser um bom candidato, é importante contar histórias, ser divertido e fazer as pessoas rirem. Nesse sentido, o candidato deve ser positivo e motivador, sabendo rir de sua própria humanidade, suas conquistas passadas, presentes e futuras, assim como de seus infortúnios.

Na verdade, o candidato deve não só possuir um bom senso de humor mas também deve dominar a arte de sorrir e fazer isso com elegância. O objetivo principal é rir com os outros, alcançando uma melhor abordagem, e não rir dos outros. Em outras palavras, deve-se ter talento para usar o humor como estratégia de campanha ou receber formação profissional para o seu domínio, já que qualquer culpa, declaração falsa ou erro podem ser facilmente detectados pelo eleitor e gerar reações contraproducentes junto aos seus colaboradores ${ }^{18}$.

Cantor observa que "o humor é uma atitude perante a vida. Quando se enfrenta os acontecimentos diários de uma forma positiva, se toma o lado do melhor humor" (Cantor, 1999, p. 80-87). Nesse sentido, os candidatos precisam sorrir e, muitas vezes, ter o sorriso à flor da pele - e, acima de tudo, fazer o público rir. Segundo Abrille (2010), o riso é ação, é socialização; evoca, comunica, expressa, diverte, e nos permite conectar-nos com a criança interior, com o jogo, com o prazer, com o movimento e com todo nosso ser (cf. Abrille, s/d).

\section{Considerações finais}

Neste estudo, analisaram-se os efeitos gerais do humor nas decisões eleitorais e políticas e na motivação do eleitor, assim como se descreveram as principais funções desempenhadas pelo humor na política. Examinou-se também a literatura existente sobre o assunto, tanto nos negócios como na política. Por fim, estudou-se a importância do humor na liderança política, no marketing e nas campanhas.

Em conclusão, pode-se dizer também que, na política, o humor tem sido utilizado desde os tempos antigos para diferentes fins, seja para criticar o poder ou para consolidá-lo. ${ }^{19}$ Sob regimes democráticos, o humor tem sido usado como estratégia de comunicação durante as campanhas eleitorais para gerenciar o afeto e conquistar o voto dos eleitores, procurando-se persuadi-los e mobilizá-los. Assim, tornou-se um elemento estratégico para que seja

\footnotetext{
que o humor pode proporcionar.

${ }_{18}$ Por exemplo, uma brincadeira também pode ser chata, confusa ou ofender alguns eleitores.

19 Por exemplo, Franklin D. Roosevelt é lembrado por seu bom senso de humor.
} 
utilizado por diferentes partidos e candidatos que disputam pelo espaço de representação pública.

No entanto, é preciso saber usar o humor já que seu mau uso ou abuso podem criar um efeito bumerangue, contra os seus utilizadores. Isso exige, da parte dos políticos, encontrar e desenvolver seu próprio estilo de humor de uma maneira natural ${ }^{20}$, evitando falsidade.

Como mencionado, a campanha eleitoral é um processo de influência, que visa conquistar, por diversos meios, o voto dos eleitores, apoiando as propostas e candidatos e votando por uma das opções apresentadas a eles. Como parte das estratégias proselitistas, usando o humor como uma fórmula de comunicação política, pois ajuda no processo de influenciar o comportamento dos eleitores.

Os efeitos gerados pelo uso apropriado do humor no comportamento dos eleitores durante as campanhas eleitorais são diversos. Primeiro, torna mais eficiente o processo de comunicação política. Segundo, facilita o processo de persuasão e diferenciação eleitoral, ajudando também a criticar e ridicularizar os adversários. Finalmente, ele gera um viés positivo na plateia, ajudando a gerar um maior nível de armazenamento das mensagens transmitidas e, acima de tudo, permite ganhar o voto dos eleitores, gerando vantagens competitivas para os seus promotores. Nesse sentido, hoje, para conquistar o poder em um sistema democrático é necessária uma boa dose de bom humor.

\section{Referências}

ABRILLE, Maria Elena Villa (s/n). "La risa y el humor, como técnicas antiestrés”. Disponível em: http://www.sexovida.com/psicologia/larisa. htm. Acessado em 16 ago. 2010.

ALDEN, Dana; MUKHERJEE, Ashesh \& HOYER, Wayne (2000). “Extending a contrast resolution model of humor in television advertising: the role of surprise". Internacional Journal of Humor Research, n. 13, p. 193-217. BELCH, George \& BELCH, Michael (1984). "An investigation of effects of repetition on cognitive and affective reactions to humorous and serious

\footnotetext{
${ }^{20}$ Alguns casos de uso indevido de humor são: 1) o imposto, que pode fazer ver o político como falso e simulador, 2) piadas ou anedotas humorísticas que geram controvérsia entre o público - piadas racistas, sexistas ou xenófobas; 3 ) as expressões humorísticas agressivas contra os adversários, que podem causar rejeição no público.
} 
television commercials". Advances in Consumer Research, n. 11, p. 4-10. BIPPUS, Amy (2007). "Factors predicting the perceived effectiveness of politicians' use of humor during a debate". International Journal of Humor Research, v. 20, n. 2, p. 105-121.

BRYANT, Jennings \& ZILLMANN, Dolf (1979). “Teachers' humor in the college classroom". Communication Education, n. 28, p. 110-118.

CANTOR, Joanne (1976). "What is funny to whom?". Journal of Communication, v. 26, n. 3, p. 164-172.

CANTOR, Joanne \& VENUS, Pat (1999). "The effects of humor or recall of a radio advertisement”. Journal of Broadcasting, n. 24, p. 80-87.

CASTELLVI, Enric (2010). "Ocho características de la dirección por la risa y el buen humor”. Disponível em http://www.rrhhmagazine.com/articulos. asp?id=493. Acessado em 01 ago. 2010.

CHATTOPADHYAY, Amitava \& BASU, Kunal (1989). "Prior brand evaluation as a moderator of the effects of humor in advertising". Journal of Marketing Research, v. 26, n. 4, p. 466-476.

CHUNG, Hwiman \& ZHAO, Xinshu (2003). "Humor effect on memory and attitude: moderating role of product involvement”. International Journal of Advertising, v. 22, n. 1, p. 117-144

CIFUENTES, Carolina M. (2005). “Tipos de humor en la publicidad impresa en Colombia”. Diversitas, v. 1, n. 1, p. 31-45.

DOUGLAS, Mary (1975). Implicit meanings. London: Routledge \& Kegan Paul.

DUNCAN, Calvin; NELSON, James \& FRONTCZAK, Nancy (1983). “The effect of humor on advertising comprehension". Advances in Consumer Research, n. 11, p. 432-437.

FINE, Gary Alan (1983). "Sociological approaches to the study of humor", em McGHEE, Paul E. \& GOLDSTEIN, Jeffrey H. (eds.). Handbook of humor research. Vol. 1. New York: Springer-Verlag.

FREUD, Sigmund (1928). "Humor”. International Journal of Psychoanalysis, n. 9, p. 1-6.

FURNHAM, Adrian (1998). "Effects of programme context on memory of humorous television commercials". Applied Cognitive Psychology, n. 12, p. 555-567.

FURSE, David \& STEWART, David (1982). "Monetary incentives versus promised contribution to charity: new evidence on mail survey 
response”. Journal of Marketing Research, n. 19, p. 375-380. GALLIVAN, Joanne (1992). "Group differences in appreciation of feminist humor”. Humor, n. 5, p. 369-374.

GELB, Betsy \& PICKETT, Charles (1983). "Attitude toward the ad: links to humor and to advertising effectiveness". Journal of Advertising, n. 12, p. 34-42.

GOLEMAN, Daniel (2001). Inteligencia emocional. Barcelona: Kairós.

LOPEZ, Sergio D. (2008). "Humor y poder: una afinidad comunicativa en el contexto social”. Revista de Antropología Iberoamericana, v. 3, v. 1, p. 64-94.

LYTTLE, Jim (2001). "The effectiveness of humor in persuasion: the case of business ethics training”. The Journal of General Psychology, v. 128, n. 2, p. 206-217.

MADDEN, Thomas J. \& WEINBERGER, Marc G. (1982). “The effects of humor on attention in magazine advertising". Journal of Advertising Research, v. 11, n. 3, p. 8-14.

(1984). "Humor in advertising: a practitioner view". Journal of Advertising Research, v. 24, n. 4, p. 23-29.

MADRIGAL, Jorge (2010). "Liderazgo con Humor", em Yoinfluo.com. Disponível em: http://www.yoinfluyo.com/index.php?option=com_conte ntఓtask=view\&id=23051\&Itemid=42. Acessado em 10 out. 2012.

MARTIN, Rod A. (2008). La psicología del humor: un enfoque integrador. Madrid: Orión.

MAXWELL, John (2009). Las 21 leyes irrefutables del liderazgo. Barcelona: RBA.

MITCHELL, Andrew \& OLSON, Jerry (1981). "Are product attribute beliefs the only mediator of advertising effects on brand attitude?". Journal of Marketing Research, n. 18, p. 318-332.

MORREALL, John (2010). "Comic vices and comic virtues". International Journal of Humor Research, v. 23, n. 1, p. 1-26.

NIETZSCHE, Friedrich (1994). Nietzsche's Philosophy of Science: reflecting science on the ground of art and life. Albany: State University of New York Press.

POWELL, John \& ANDRESEN, Lee (1985). "Humour and teaching in higher education”. Studies in Higher Education, v. 10, n. 1, p. 79-89.

RAY, Michael \& BATRA, Rajeev (1983). "Emotion and persuasion in 
advertising: what we do and don't know about affect". Advances in Consumer Research, n. 10, p. 24-38.

REBOUX, Paul \& MULLER, Charles (1950). A la manière de... Paris: Grasset $\&$ Fasquelle.

RITZ, Sandra E. (2004). "El humor del superviviente: el papel del humor al enfrentarse las personas con los desastres”, em SALAMEH, Waleed \& FRY,William (coords.). El humor y el bienestar en las intervenciones clínicas. Bilbao: Desclee de Brouwer.

ROPERTO, Juan (s/d). "Humor político". Disponível em: http://www. monografias.com/trabajos15/humor-politico/humor-politico.shtml. Acessado em 14 jul. 2010.

SANCHEZ, Alberto (2007). "Freud y Bergson: el chiste y la risa y su relación con lo social". Arbor, v. 183, n. 723, p. 103-121.

SCOTT, Cliff; KLEIN, David. M. \& BRYANT, Jennings (1990). “Consumer response to humor in advertising: a series of field". Journal of Consumer Research, v. 16, n. 4, p. 498-501.

SMITH, Robert E. (1993). "Integrating information from advertising and trial: processes and effects on consumer response to product information". Journal of Marketing Research, n. 30, p. 204-219.

SYLVESTER, Alice K. (2000). "Make'em laugh, make'em buy”. Advertising Age, n. 71, p. 20-25.

TERRY, Roger \& ERTEL, Sarah (1974). "Exploration of individual differeneces in preferences for humor". Psychological Reports, v. 34, n. 3c, p. 1030-1037.

TSAKONA, Villy (2009). "Humor and image politics in parliamentary discourse: a Greek case study". Text \& Talk, v. 29, n. 2, p. 219-237.

VASIL'EVICH, Anatolii (2005). "Humor and politics". Anthropology \& Archeology of Eurasia, v. 44, n. 3, p. 64-100.

WEINBERGER, Marc G.; CAMPBELL, Leland \& PARSONS, Amy (1995). "The use and effect of humor in different advertising media". Journal of Advertising Research, v. 35, n. 3, p. 44-54.

WEINBERGER, Marc G. \& CAMPELL, Leland (1991). "The use and impact of humor in radio advertising". Journal of Advertising Research, v. 31, n. 1, p. 644-652.

WEINBERGER, Marc \& GULAS, Charles S. (1992). “The impact of humor in advertising: a review". Journal of Advertising, n. 21, p. 35-59. 
ZHANG, Yong \& Zinkhan, George (1991). "Humor in television advertising: the effects of repetition and social setting". Advances in Consumer Research, n. 18, p. 813-818.

ZHANG, Yong (1996). "Responses to humorous advertising: the moderating effect of need for cognition". Journal of Advertising, n. 25, p. 15-29.

\section{Resumo}

Realiza-se uma análise do uso do humor como parte das estratégias de persuasão na liderança e na política, em geral, e nas campanhas eleitorais em particular. Aborda-se também o estudo das funções desempenhadas pelo humor nas campanhas eleitorais e as razões pelas quais este é usado como parte de estratégias para convencer os eleitores. Examinou-se também a literatura especializada e as investigações já realizadas sobre o assunto, tanto nos negócios como na política. Finalmente, concluiu-se que, sob regimes democráticos, o humor tem sido utilizado como estratégia de comunicação durante as campanhas eleitorais para gerenciar o afeto e conquistar o voto dos eleitores, procurando persuadí-los e mobilizá-los.

Palavras-chave: Humor, estratégias de persuasão política, liderança, marketing político, campanhas eleitorais, funções do humor, sistemas democráticos, poder político.

\section{Abstract}

In this paper we analyze the use of humor as part of the strategies of persuasion in leadership and politics in general, and in election campaigns and the political marketing, in particular. It addresses also the study of the functions performed by the humor in election campaigns and the reasons why it is used as part of the strategies of persuasion of voters. We examine also the literature and research that has been done on the subject, both in business and in politics. Finally, we conclude that under democratic regimes, humor has been used as a marketing strategy during election campaigns to manage the affection and win the vote of the voters, seeking to persuade and mobilize.

Keywords: Humor, persuasion strategies in politics, leadership, political marketing, election campaigns, humor functions, democratic systems, political power.

Recebido em 30 de janeiro de 2012.

Aprovado em 19 de março de 2012. 